\title{
Pharmacological Management Evolution of Type 2 Diabetes Mellitus: Focus on Cardiovascular Outcomes Trials from 2013 to 2020 and Their Impact on Practice Guidelines
}

\author{
Enrique C Morales-Villegas* \\ Cardiometabolic Research Center, Aguascalientes, Mexico
}

*Corresponding author: Morales-Villegas EC, MD, Cardiometabolic Research Center, Aguascalientes, Mexico, Tel: +524499782545; E-mail: drmorvi@prodigy.net.mx

Received: 08 Jun, 2020 | Accepted: 25 Jun, 2020 | Published: 30 Jun, 2020

Citation: Morales-Villegas EC (2020) Pharmacological Management Evolution of Type 2 Diabetes Mellitus: Focus on Cardiovascular Outcomes Trials from 2013 to 2020 and Their Impact on Practice Guidelines. J Hear Health 6(1): dx.doi.org/10.16966/2379-769X.154

Copyright: (C) 2020 Morales-Villegas EC. This is an open-access article distributed under the terms of the Creative Commons Attribution License, which permits unrestricted use, distribution, and reproduction in any medium, provided the original author and source are credited.

\begin{abstract}
In this brief review of the recent evolution of the pharmacological treatment of Type 2 Diabetes Mellitus (T2DM), we will analyze how different ways of living with diabetes coexist around the world. To define them, we will use the concept that we have called the three contemporary visions of T2DM, namely: dark vision, luminous vision, and bright vision. We will also discuss how the glucocentric paradigm of T2DM treatment led to the development, implementation, and publication of the Cardiovascular Outcomes Trials (CVOTs) in T2DM. Since June 2013, eighteen CVOTs have been published that have studied the cardiovascular safety of fifteen anti-diabetic drugs belonging to four new therapeutic classes. Together, these studies have included more than 150,000 individuals with a cumulative average follow-up of almost half a million patient-years. These studies have shown that beyond glycemic control, six drugs-Empagliflozin, Canagliflozin, Dapagliflozin, Liraglutide, Semaglutide, and Dulaglutide belonging to two new therapeutic classes, significantly reduce the cerebrovascular, cardiovascular, and renal morbidity and mortality of T2DM patients. Thus, establishing a new paradigm in the pharmacological treatment of T2DM, the paradigm of cerebral and cardio-renal protection of the diabetic individual. This substantial evidence has been transferred to the T2DM practice guidelines and, for the first time in this medical field, has been homologated around the world.
\end{abstract}

Keywords: Type 2 diabetes mellitus; Cardiovascular outcomes trials; DPP4 inhibitors; SGLT2 inhibitors; GLP1 receptor agonists

\section{Introduction}

At least three visions on the management of T2DM and its associated cardiovascular risk coexist simultaneously. We have described these visions as dark, luminous, and bright. The dark vision represents a scenario with a plethora of micro and macrovascular complications such as blindness, stroke, myocardial infarction, dialysis, amputations, and premature death. Unfortunately, in some countries, the dark vision is still a reality. A clear example is the Mexico City Study Trial, published by Alegre Diaz J, et al. in 2016 [1]. In this study, individuals from 35 to 59 years with diabetes had a higher risk of death than individuals with the same age but without diabetes. Furthermore, having diabetes was associated with a rate ratio for renal death 31.1 times higher, cardiovascular death 4.6 times higher, and for cerebrovascular death 4.6 times higher. These results are unacceptable in this century. The dark vision is primarily determined by late diagnosis and a delayed, glucocentric, and insufficient treatment, which ensures a poor prognosis.

The luminous vision is exemplified by the Steno-2 Study published by Gaede P, et al. [2-4]. This study was published in 2008 and had a follow-up of 13.3 years [3]. A multifactorial, targeted, and intensified intervention reduced the relative risk of total and cardiovascular death by $46 \%$ and $59 \%$, respectively. Their therapeutic approach was characterized by a blood pressure $<130 / 80 \mathrm{mmHg}$, HbAlc $<6.5 \%$, total cholesterol $<175 \mathrm{mg} / \mathrm{dl}$, and triglycerides $<150 \mathrm{mg} / \mathrm{dL}$. These are difficult but not impossible numbers nowadays. The Swedish National Diabetes Register showed us another example of the luminous vision [5,6]. In this 2018 report published by Rawshani A, et al. [6], the risk of total death in a subgroup with T2DM was equal to the risk of individuals without T2DM, with a non significant hazard ratio of 1.06 (1.0 to 1.12). Similarly to the Steno-2 Study, the profile of this subgroup of patients was characterized by a blood pressure $<140 / 80$ $\mathrm{mmHg}, \mathrm{HbA1c}<7 \%$, low-density lipoprotein cholesterol $<100 \mathrm{mg} /$ $\mathrm{dL}$, no smoking habit, and no albuminuria. Again, these are difficult but achievable goals. Unlike the dark vision, early diagnosis and a prompt, multifactorial, intensified, and sufficient treatment ensures an excellent prognosis.

Finally, we will address what a bright vision means. The development of new anti-diabetic drugs reducing cerebral, cardiac, and renal risks 
predicts a great future for T2DM. Very recently, the Danish National Patient Registry [7] published their results for different treatment strategies in real life high-risk patients. A combination of Metformin plus a glucagon-like peptide 1 receptor agonist (Liraglutide in $97 \%$ of the cases) reduced by $42 \%$ the Major Adverse Cardiovascular Events (MACE) risk when compared with a combination of metformin plus sulfonylurea.

According to the evidence published in the last seven years, in 2020 we can significantly reduce the morbidity and mortality of individuals with T2DM. This can be achieved by decreasing the incidence of cardiovascular death, myocardial infarction, stroke, heart failure hospitalization, and chronic kidney disease progression with the use of six new drugs of two different pharmacological groups, thus establishing a new paradigm in medicine [8] (Figure 1).

\section{Pharmacological Management Evolution}

\section{Steering away from the glucocentric paradigm}

In 2008, the glucocentric paradigm established that reducing $\mathrm{HbAlc}$ levels would also reduce disability caused by retinopathy, nephropathy, and neuropathy. This was the paradigm for almost a century. The symbol of the glucocentric paradigm was the United Kingdom Prospective Diabetes Study (UKPDS) [9]. This study showed that reducing $1 \%$ of $\mathrm{HbAlc}$, would produce a $37 \%$ risk reduction of microangiopathy and a $14 \%$ risk reduction of myocardial infarction. Years later, the trials ACCORD, ADVANCE, and VADT [10-12] demonstrated that an intensive strategy based on $\mathrm{HbAlc}$ control was not more effective than one standard strategy for the risk reduction of fatal and non-fatal cardiovascular events. Beyond that result, the ACCORD trial showed a significant increase in fatal cardiovascular events in the intensive strategy group [10]. In 2007, Nissen SE, et al. reported a significantly increased risk of $43 \%$ for cardiovascular death or myocardial infarction in patients treated with Rosiglitazone versus other treatments or controls [13]. This trial concluded, "The ultimate value of anti-diabetic therapy is the reduction of the complications of diabetes, not the improvement of a laboratory measure of glycemic control such as HbAlc".

\section{Birth of Cardiovascular Outcomes Trials (CVOTs) in Type 2 Diabetes Mellitus}

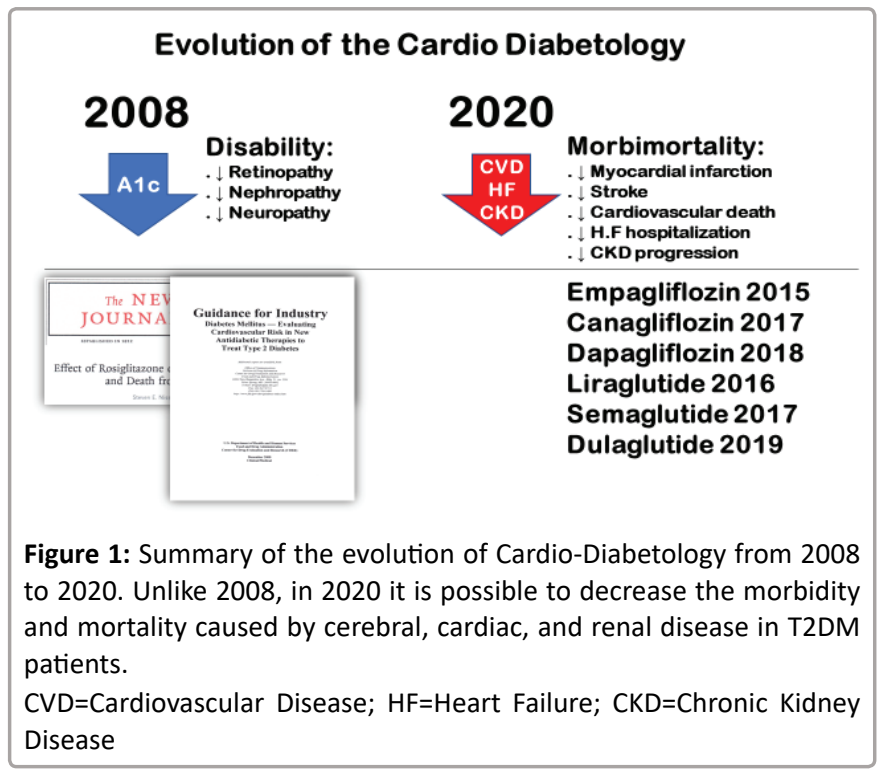

Reactively, in December 2008, the Federal Drug Administration (FDA) published its first guideline for the industry entitled diabetes mellitus-evaluating cardiovascular risk in new anti-diabetic therapies to treat type 2 diabetes mellitus [14]. In this guideline, the FDA recommended designing double-blinded (placebo versus active treatment) cardiovascular outcomes trials in T2DM. The trials would include metabolically uncontrolled patients, with risk or with cardiovascular disease treated with the standard of care, with an HbAlc goal of $<7 \%$ in both groups. An independent adjudication committee would then evaluate the incidence of the so-called 3-point MACE (Major Adverse Cardiovascular Events), being cardiovascular death, myocardial infarction, and stroke.

The agreed and recommended interpretation of the CVOTs results was simple. If the upper limit of the confidence interval for the 3-point MACE Hazard Ratio (HR) was:

- 1.8 or higher, the drug is inferior and rejected to be marketed

- $\quad$ Equal to or higher than 1.3 and $<1.8$, the drug is inferior and conditioned to demonstrate non-inferiority

- Equal to or higher than 1.0 but $<1.3$ the drug is classified as non-inferior or safe and could be marketed

- $\quad<1.0$, the drug is superior or protective and should be marketed

Under this guideline, from June 2013 to December 2019, eighteen CVOTs have been published. This is truly an amazing explosion of high-quality evidence. In seven years, more than 157,000 individuals have been included in eighteen CVOTs [15-32], with a follow up of almost half a million patient-years. This is an incredible achievement in clinical research.

In the following section, we will discuss the main CVOTs results published as of May 2020 for dipeptidyl peptidase 4 inhibitors; sodiumglucose transporters type 2 inhibitors and, more extensively, glucagonlike peptide 1 receptor agonists. We will only include the glucagon-like peptide 1 receptor agonists that are currently marketed. CVOTs for insulin analogs (DEVOTE trial) are not discussed in this review.

\section{Cardiovascular outcomes trials for Dipeptidyl Peptidase 4 Inhibitors (DPP-4i)}

There are five CVOTs with DPP-4i [15-19], with more than 49,000 patients included. All CVOTs showed non-inferiority, but none showed superiority compared to placebo. That means that all DPP-4i are safe therapies for glycemic control, with neither reduction nor increase of the cerebral, cardiac, or renal risk in T2DM patients. However, as an exception, Saxagliptinin the SAVOR trial [15] increased by $27 \%$ the relative risk for heart failure hospitalization (Figure 2, Table 1).

\section{Cardiovascular outcomes trials for Sodium-Glucose Transporters Type 2 inhibitors (SGLT2i)}

There are five CVOTs with SGLT2i [27-31], with more than 43,000 patients included.There is some heterogeneity in the results. Dapagliflozin in the DECLARE trial [30] did not reduce the 3-point MACE risk, while Empagliflozin in the EMPA-REG trial [27] and Canagliflozin in the CANVAS trial [28] did. In the DECLARE trial, Dapagliflozin only reduced the 2-point MACE risk of cardiovascular death and/or heart failure hospitalization. In the CREDENCE trial [29], Canagliflozin reduced the four Mayor Adverse Renal Events (4-point MARE) risk in Chronic Kidney Disease (CKD) patients with macroalbuminuria; while in the DAPA-HF trial [31], Dapagliflozin reduced the 2-point MACE of cardiovascular death and/or heart failure deterioration in patients with systolic heart failure with or 


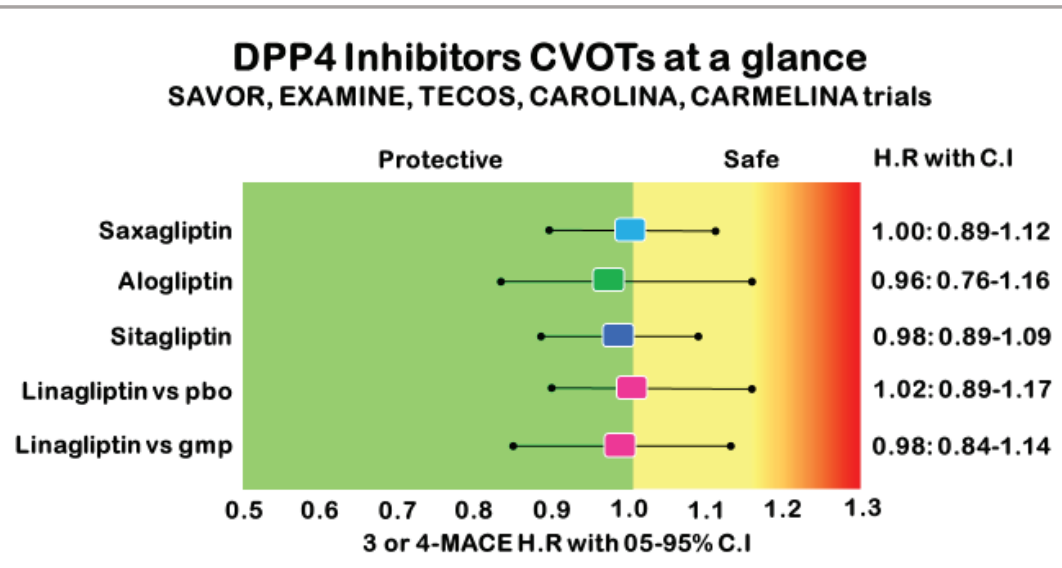

Figure 2: Summary of the primary end-point results with the four DPP-4i studied in five CVOTs. In all CVOTs the upper limit of the confidence interval of the hazard ratio for the 3-point or 4-point MACE was higher than 1.0 and lower than 1.3 which means non-inferiority or safety. CVOTs=Cardiovascular Outcomes Trials; pbo=Placebo; gmp=Glimepiride; MACE=Major Adverse Cardiovascular Events; H.R=Hazard Ratio; C.I=Confidence Interval

\begin{tabular}{|c|c|c|c|c|c|}
\hline & SAVOR & EXAMINE & TECOS & CARMELINA & CAROLINA \\
\hline Publication & $\begin{array}{l}\text { NEJM } \\
2013 ; 369: 1317-26\end{array}$ & $\begin{array}{l}\text { NEJM } \\
\text { 2013; 369:1327-35 }\end{array}$ & $\begin{array}{l}\text { NEJM } \\
\text { 2015; 373:232-4 }\end{array}$ & $\begin{array}{l}\text { JAMA } \\
2018 \text { online nov } 9\end{array}$ & $\begin{array}{l}\text { JAMA } \\
2019 \text { online sep. } 19\end{array}$ \\
\hline Number included & 16,492 & 5,380 & 14,735 & 6,991 & 6,042 \\
\hline Clinical profile & $\begin{array}{l}\text { CVD/High risk } \\
78 / 22 \%\end{array}$ & $\begin{array}{l}\text { CVD post-ACS } \\
100 \%\end{array}$ & $\begin{array}{l}\text { CVD } \\
100 \%\end{array}$ & $\begin{array}{l}\text { CVD/CKD } \\
57 / 74 \%\end{array}$ & $\begin{array}{l}\text { CVD/High risk } \\
35 / 75 \%\end{array}$ \\
\hline $\begin{array}{l}\text { Drug } \\
\text { Dose }\end{array}$ & $\begin{array}{l}\text { Saxagliptin } \\
2.5 / 5 \mathrm{mg} / \text { day }\end{array}$ & $\begin{array}{l}\text { Alogliptin } \\
6.25 / 12.5 / 25 \mathrm{mg} / \text { day }\end{array}$ & $\begin{array}{l}\text { Sitagliptin } \\
50 / 100 \mathrm{mg} / \text { day }\end{array}$ & $\begin{array}{l}\text { Linagliptin } \\
5 \mathrm{mg} / \text { day }\end{array}$ & $\begin{array}{l}\text { Linagliptin//Glimepiride } \\
5 \mathrm{mg} / \text { day//1-4mg/day }\end{array}$ \\
\hline Primary outcome & 3-MACE & 3-MACE & 4-MACE & 3-MACE & 3-MACE \\
\hline Follow-up -average- & 2.1 years & 1.5 years & 3 years & 2.2 years & 6.5 years \\
\hline Age -average- & 65.1/65.0 years & 61.0/61.0 years & 65.4/65.5 years & 66.1/65.6 years & 63.9/64.2 years \\
\hline Female gender $-\%$ - & $33.4 / 32.7 \%$ & $22.3 / 22.0 \%$ & $29.1 / 29.5 \%$ & $38.5 / 35.7 \%$ & $39.2 / 40.8 \%$ \\
\hline Hispanics -\%- & $21.5 / 21.5 \%$ & $25.9 / 25.9 \%$ & $12.1 / 12.4 \%$ & $33.1 / 33.1 \%$ & $17.2 / 17.1 \%$ \\
\hline Body mass index & $31.1 / 31.1 \mathrm{k} / \mathrm{m} 2$ & $28.7 / 28.7 \mathrm{k} / \mathrm{m} 2$ & $30.2 / 30.2 \mathrm{k} / \mathrm{m} 2$ & $31.4 / 31.3 \mathrm{k} / \mathrm{m} 2$ & $30.2 / 30.0 \mathrm{k} / \mathrm{m} 2$ \\
\hline T2DM duration & 10.3/10.3 years & $7.1 / 7.3$ years & 11.6/11.6 years & $15.0 / 14.5$ years & 6.3/6.2 years \\
\hline Baseline HbA1c & $8.0 / 8.0 \%$ & $8.0 / 8.0 \%$ & $7.2 / 7.2 \%$ & $7.9 / 8.0 \%$ & $7.2 / 7.2 \%$ \\
\hline $\begin{array}{l}\text { Primary outcome HR } \\
\text { P value }\end{array}$ & $\begin{array}{l}\text { 1: } 0.89 \text { a } 1.12 \\
\text { P: } 0.99 \text { for superiority }\end{array}$ & $\begin{array}{l}0.96:- \text { a } 1.16 \\
\text { P: } 0.32 \text { for superiority }\end{array}$ & $\begin{array}{l}0.98: 0.89 \text { a } 1.08 \\
\text { P: } 0.65 \text { for superiority }\end{array}$ & $\begin{array}{l}1.02: 0.89 \text { a } 1.17 \\
\text { P: } 0.74 \text { for superiority }\end{array}$ & $\begin{array}{l}0.98: 0.84-1.14 \\
P: 0.76 \text { for superiority }\end{array}$ \\
\hline Annual risk -average- & $3.7 / 3.7 \%$ & $7.5 / 7.5 \%$ & $4.0 / 4.1 \%$ & $5.715 .6 \%$ & $2.1 / 2.1 \%$ \\
\hline
\end{tabular}

Table 1: Main characteristics and results of the five CVOTs with DPP-4i.

CVD=Cardiovascular Disease; CKD=Chronic Kidney Disease; 3-MACE=Mayor Adverse Cardiovascular Events including cardiovascular death, myocardial infarction, and stroke; 4-MACE=3-MACE plus hospitalization for unstable angina

without T2DM. In conclusion, all the SGLT2i, in different magnitude, reduced the cerebral, cardiac, and renal risk in patients with T2DM (Figure 3, Table 2).

\section{Cardiovascular outcomes trials for Glucagon-Like Peptide 1 Receptor agonists (GLP1-RA)}

Human Glucagon-Like Peptide 1 (GLP1) is a polypeptide with 31 amino acids, a molecular weight of 3.6 kilodaltons, secreted by the intestinal L cells, with a half-life of just 2 minutes. This polypeptide is bonded to the GLP1 receptor in the extreme C-terminal of the molecule and is proteolyzed by dipeptidyl peptidase 4 , especially in the 7-8 and $24-25$ positions [33].
There are seven CVOTs [20-26], with more than 50,000 patients included. So far, this is the most studied group.

\section{GLP1-RA, exendin-4 derivatives:}

The first GLP1-RA was Exenatide. Exenatide is a synthetic exendin-4, which was initiallyobtained from the Gila monster saliva. This GLP1-RA is a molecule with 39 amino acids, with 53\% shared homology to the human GLP1, and a molecular weight of 4.10 kilodaltons. In the EXSCEL trial [24], Exenatide compared to placebo was non-inferior but was not superior in the reduction of the 3-point MACE. Lixisenatide is another GLP1-RA derived from exendin-4. This molecule has 45 amino acids, only 50\% shared homology to the 


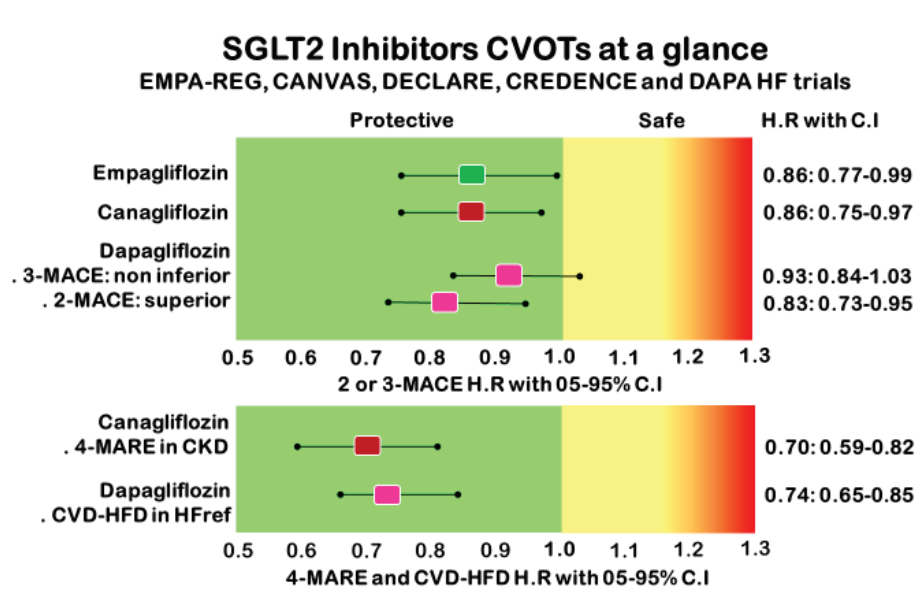

Figure 3: Upper panel: Primary end-point results with the three SGLT2-I studied in three CVOTs. Empagliflozin and Canagliflozin demonstrated superiority or efficacy; Dapagliflozin was non-inferior or safe for 3-point MACE and had better results for 2-point MACE reduction of heart failure hospitalization and cardiovascular death.

Lower panel: In individuals with Chronic Kidney Disease (CKD) and macroalbuminuria, Canagliflozin was superior in the 4-point MARE reduction; Dapagliflozin was superior in the 2-point MACE reduction of Cardiovascular Death (CVD) and Heart Failure Deterioration (HFD) in individuals with heart failure with reduced ejection fraction (HFref).

MACE=Major Adverse Cardiovascular Events; MARE=Major Adverse Renal Events; H.R=Hazard Ratio; C.I=Confidence Interval

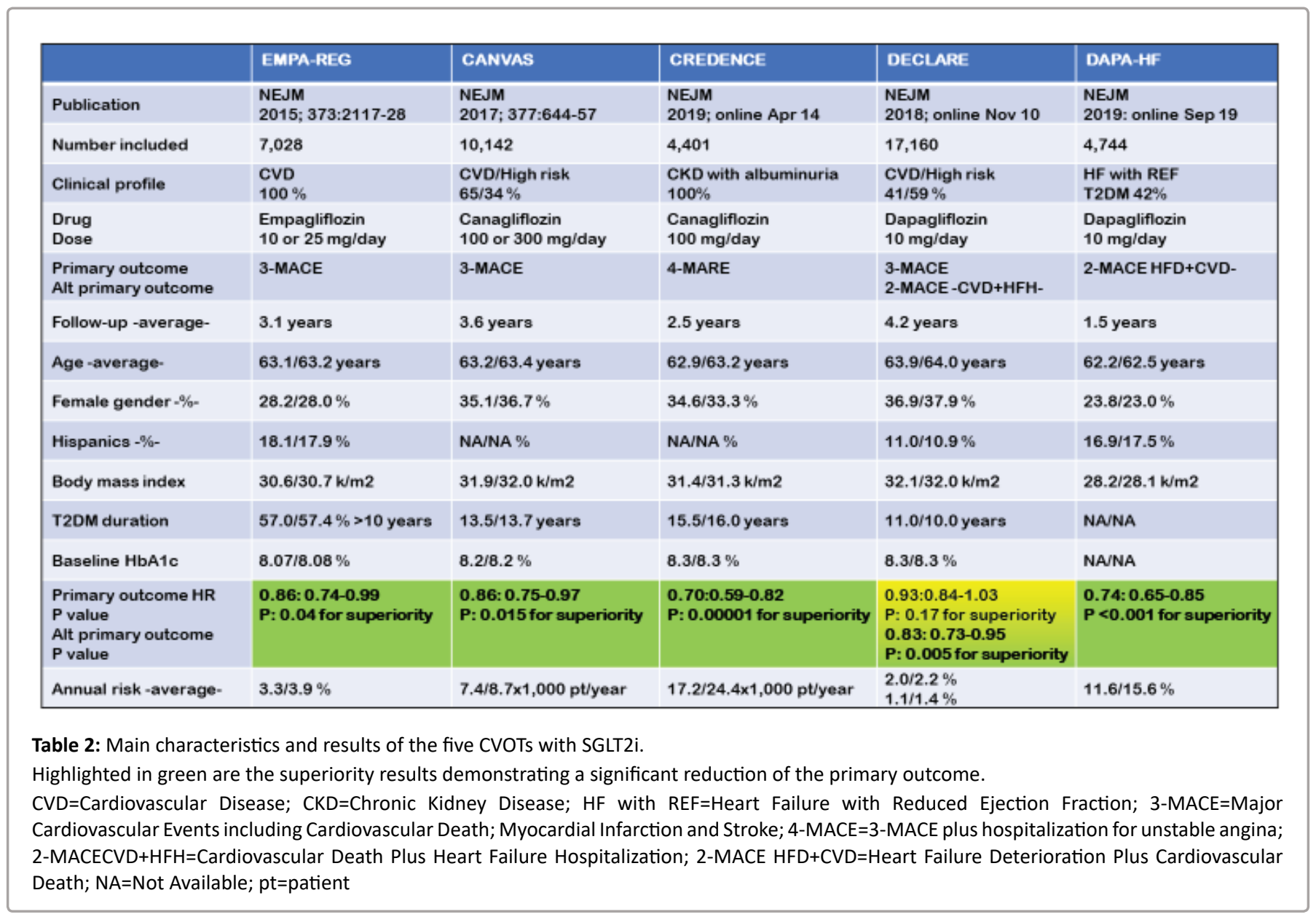

Citation: Morales-Villegas EC (2020) Pharmacological Management Evolution of Type 2 Diabetes Mellitus: Focus on Cardiovascular Outcomes Trials from 2013 to 2020 and Their Impact on Practice Guidelines. J Hear Health 6(1): dx.doi.org/10.16966/2379-769X.154 
human GLP1, and a molecular weight of 4.8 kilodaltons. In the ELIXA trial [20], Lixisenatide compared to placebo, like Exenatide, was noninferior but was not superior in the reduction of the 4-point MACE (Figure 4).

\section{GLP1-RA analogs:}

Liraglutide is a GLP1 analog with 31 amino acids, shares $97 \%$ homology tohuman GLP1, and a molecular weight of 3.7 kilodaltons. The half-life is 14 hours therefore, it can be administered once a day. Liraglutide substitutes lysine for glutamine at position 26 protecting from DPP4 action, and at this position, a 16-carbon fatty acid is attached binding to albumin. Atposition 34, Liraglutide has a substitution of lysine for arginine, which inhibits the ectopic binding of the 16-carbon fatty acid.

In the LEADER trial [21], Liraglutide showed for the first time noninferiority and significant superiority compared to placebo. It had an absolute 3-point MACE risk reduction of 1.9\%, with a Number Needed to Treat (NNT) of 52 in 3.8 years. In the 3-point MACE analysis, Liraglutide significantly reduced the risk of cardiovascular death with an absolute reduction of $1.3 \%$ with an NNT of 76 in 3.8 years. As of today, Liraglutide is the only GLP1-RA with this ability.

Semaglutide is another GLP1 analog with 31 amino acids, shares $94 \%$ homology to the human GLP1, and a molecular weight of 4.1 kilodaltons. The half-life is 160 hours therefore, it can be administered once a week. Unlike Liraglutide, Semaglutide substitutes an aminobutyric acid for alanine at position 8 protecting from the DPP4 action. At position 26, it has a linker with an 18-carbon fatty acid, which allows a tight binding to albumin. Like Liraglutide, it has a substitution of lysine for arginine at position 34 which inhibits the ectopic binding of the 18-carbon fatty acid.

In the SUSTAIN 6 trial [22], Semaglutide showed, compared to placebo, non-inferiority, and significant superiority, with an absolute 3 -point MACE risk reduction of 2.3\%with an NNT of 42 in 2.1 years. In the 3-point MACE analysis, Semaglutide significantly reduced the risk of stroke, with an absolute reduction of $1.1 \%$ with an NNT of 90 in 2.1 years.

Albiglutide is another analog of the human GLP1, unlike Liraglutide and Semaglutide, Albiglutide has 62 amino acids, as it is built with 2 linked GLP1. Albiglutide substitutes alanine for glycine and is attached to one molecule of albumin; for that reason, Albiglutide has a high molecular weight of 72.9 kilodaltons. In the HARMONY trial [25], Albiglutide compared to placebo also showed non-inferiority and superiority in the reduction of the 3-point MACE risk. Unfortunately, Albiglutide is not marketed around the world.

Finally, Dulaglutide is a complex analog of the human GLP1, like Albiglutide it is built with 2 linked GLP1. Dulaglutide contains 3 amino acid substitutions and is attached through 2 peptides to a crystallizable fragment of an immunoglobulin $G$ type 4 . Hence, Dulaglutide, like Albiglutide, has a high molecular weight of 59.6 kilodaltons. In the REWIND trial [26], Dulaglutide compared to placebo, also demonstrated superiority in the reduction of the 3-point MACE risk (Figure 4).

There are essential differences between the GLP1-RAs. GLP1 analogs (Liraglutide, Semaglutide, Albiglutide, and Dulaglutide) reduce the cerebral, cardiac, and renal risk in T2DM. Exendin-4 derivatives (Exenatide and Lixisenatide) do not reduce this risk. Among the analogs, Liraglutide is the only one that reduces the 3-point MACE with a significant reduction of cardiovascular death (Figure 4, Table 3).

With the publication of the CVOTs with GLP1-RA, one could ask,how does GLP1-RA reduce the cardiovascular risk? Many researchers [34-38] have proposed complementary frameworks to explain the cardiovascular actions and clinical outcomes with GLP1RA. In brief, we know that GLP1 increases insulin secretion, decreases glucagon secretion, increases satiety, and decreases gastric emptying. Therefore, having positive results on body weight, hemodynamic, and metabolic cardiovascular risk factors. Beyond those classical actions, GLP1 analogs have a cardioprotective effect against ischemia and positive effects over chronotropism and inotropism. On the endothelium, they have positive effects on angiogenesis and vasodilation. Significant anti-inflammatory and anti-platelet effects have been reported. In summary, GLP1 analogs seem to have an anti-atherosclerotic effect, a concept recently reinforced by animal experiments in mice [39] (Figure 5).

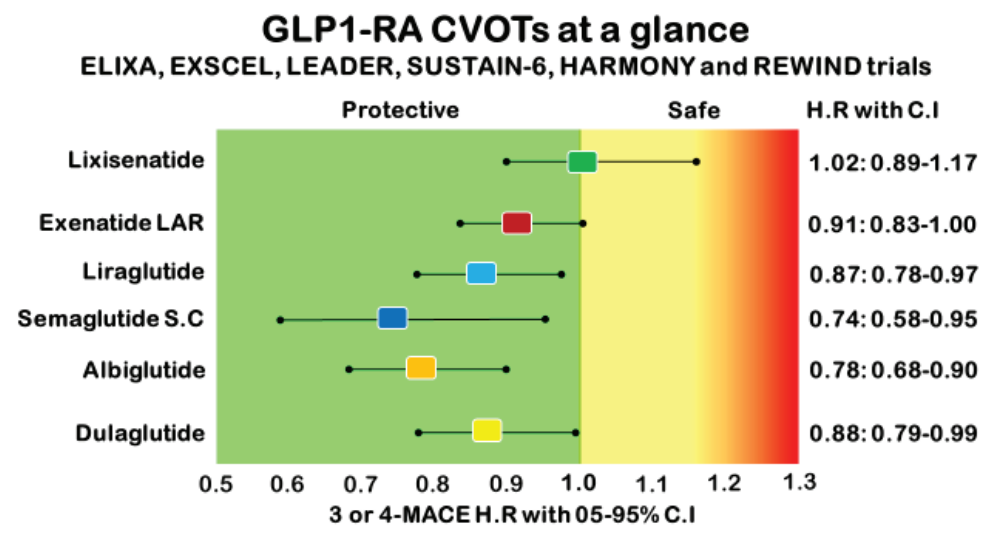

Figure 4: Summary of the primary end-point results of the six GLP1-RA studied in six CVOTs. Lixisenatide and Exenatide (exendin-4 derivatives) like DPP-4i demonstrated non-inferiority or safety. GLP1 analogs (Liraglutide, Semaglutide, Albiglutide and Dulaglutide) demonstrated superiority or efficacy. Oral Semaglutide (PIONEER 6 trial) is not included since its definitive CVOT (SOUL trial) is ongoing.

CVOTs=Cardiovascular Outcomes Trials; MACE=Major Adverse Cardiovascular Events; H.R=Hazard Ratio, C.I=Confidence Interval 


\begin{tabular}{|c|c|c|c|c|c|}
\hline & ELIXA & LEADER & SUSTAIN 6 & EXSCEL & REWIND \\
\hline Publication & $\begin{array}{l}\text { NEJM } \\
\text { 2015; 373:2247-57 }\end{array}$ & $\begin{array}{l}\text { NEJM } \\
2016 ; 375: 311-22\end{array}$ & $\begin{array}{l}\text { NEJM } \\
2016 ; 375: 1834-44\end{array}$ & $\begin{array}{l}\text { NEJM } \\
2017 ; 377: 1228-1239\end{array}$ & $\begin{array}{l}\text { Lancet } \\
\text { 2019; online Jun } 10\end{array}$ \\
\hline Number included & 6,068 & 9,340 & 3,297 & 14,752 & 9,901 \\
\hline Clinical profile & $\begin{array}{l}\text { CVD post-ACS } \\
100 \%\end{array}$ & $\begin{array}{l}\text { CVD-CKD/High risk } \\
82 / 18 \%\end{array}$ & $\begin{array}{l}\text { CVD-CKD/High risk } \\
83 / 17 \%\end{array}$ & $\begin{array}{l}\text { CVD/High risk } \\
73 / 27 \%\end{array}$ & $\begin{array}{l}\text { CVD/High risk } \\
31.5 / 68.5\end{array}$ \\
\hline $\begin{array}{l}\text { Drug } \\
\text { Dose }\end{array}$ & $\begin{array}{l}\text { Lixisenatide } \\
10 \text { a } 20 \text { ug/SC day }\end{array}$ & $\begin{array}{l}\text { Liraglutide } \\
1.8 \mathrm{mg} / \mathrm{SC} \text { day }\end{array}$ & $\begin{array}{l}\text { Semaglutide } \\
0.5 \text { or } 1.0 \mathrm{mg} / \mathrm{SC} \text { week }\end{array}$ & $\begin{array}{l}\text { Exenatide LAR } \\
2 \mathrm{mg} / \mathrm{SC} \text { week }\end{array}$ & $\begin{array}{l}\text { Dulaglutide } \\
1.5 \mathrm{mg} / \mathrm{SC} \text { week }\end{array}$ \\
\hline Primary outcome & 4-MACE & 3-MACE & 3-MACE & 3-MACE & 3-MACE \\
\hline Follow-up -average- & 2.1 years & 3.8 years & 2.1 years & 3.2 years & 5.4 years \\
\hline Age & $59.9 / 60.6$ years & $64.2 / 64.4$ years & $64.6 / 64.7$ years & 62.0/62.0 years & 66.2/66.2 years \\
\hline Female gender - $\%$ - & $30.4 / 30.9 \%$ & $25.5 / 26.0 \%$ & $39 / 40 \%$ & $38.0 / 38.0 \%$ & $46.4 / 46.4 \%$ \\
\hline Hispanics = $\%$ - & $28.5 / 29.8 \%$ & $27.2 / 26.1 \%$ & $16.0 / 15.0 \%$ & $20.5 / 20.6 \%$ & $32.3 / 32.3 \%$ \\
\hline Body mass index & $30.1 / 30.2 \mathrm{k} / \mathrm{m} 2$ & $32.5 / 32.5 \mathrm{k} / \mathrm{m} 2$ & $30.8 / 32.7 \mathrm{k} / \mathrm{m} 2$ & $31.8 / 31.7 \mathrm{k} / \mathrm{m} 2$ & $32.3 / 32.3 \mathrm{k} / \mathrm{m} 2$ \\
\hline T2DM duration -average- & 9.2/9.4 years & $12.8 / 12.9$ years & 14.3/14.1 years & $12.0 / 12.0$ years & 10.5/10.5 years \\
\hline Baseline HbA1c & $7.7 / 7.6 \%$ & $8.7 / 8.7 \%$ & $8.7 / 8.7 \%$ & $8.0 / 8.0 \%$ & $7.2 / 7.2 \%$ \\
\hline $\begin{array}{l}\text { Primary outcome HR } \\
\text { P value }\end{array}$ & $\begin{array}{l}\text { 1.02: } 0.89 \text { a } 1.17 \\
\text { P: } 0.81 \text { for superiority }\end{array}$ & $\begin{array}{l}0.87: 0.78 \text { a } 0.97 \\
P: 0.01 \text { for superiority }\end{array}$ & $\begin{array}{l}0.74: 0.58 \text { a } 0.95 \\
\text { P: } 0.02 \text { for superiority }\end{array}$ & $\begin{array}{l}0.91: 0.83 \text { a } 1.0 \\
P: 0.06 \text { for superiority }\end{array}$ & $\begin{array}{l}0.88: 0.79-0.99 \\
\text { P 0.026 for superiority }\end{array}$ \\
\hline Annual risk & $6.4 / 6.3 \%$ & $3.4 / 3.9 \%$ & $3.2 / 4.4 \%$ & $3.7 / 4.0 \%$ & $2.4 / 2.7 \%$ \\
\hline
\end{tabular}

Table 3: Main characteristics and results of the five CVOTs with marketed GLP1-RAi.

Highlighted in green are the superiority results demonstrating a significant reduction of the primary outcome. Albiglutide results (HARMONY trial) are not included since it is not marketed, nor oral Semaglutide (PIONEER 6 trial) since its definitive CVOT (SOUL trial) is ongoing.

CVD post ACS=Cardiovascular Disease Post-Acute Coronary Syndrome; CVD=Cardiovascular Disease; CKD=Chronic Kidney Disease; 3-MACE =Major Cardiovascular Events including Cardiovascular Death; Myocardial Infarction, and Stroke; 4-MACE=3-MACE plus hospitalization for unstable angina

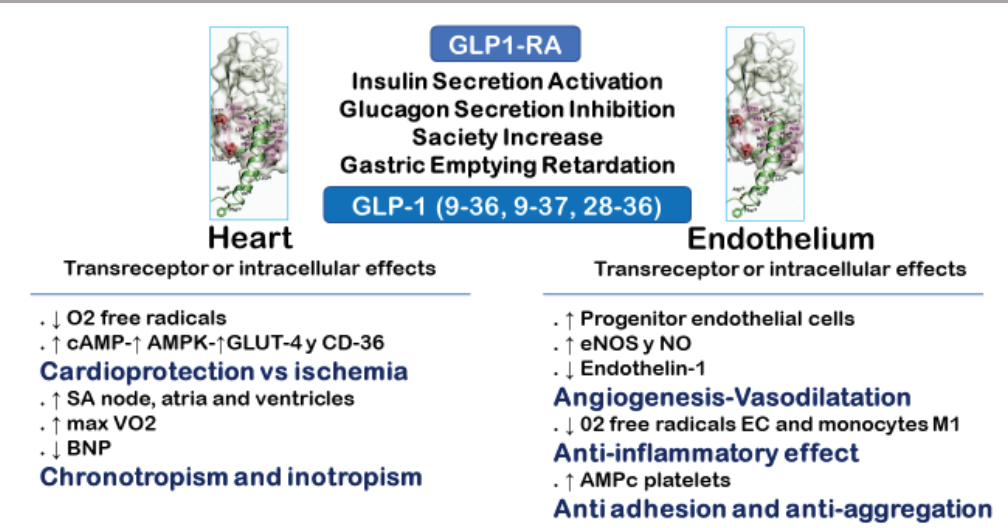

Figure 5: Summary of the "classic" effects of the GLP1 receptor agonists. Also summarized, the most studied effects on the heart and the endothelium. All these actions produce an anti-atherosclerotic effect.

\section{Adverse Effects and Risk Profile}

Regarding the general safety and tolerance of the previous antidiabetic drugs, the guidelines highlight the following:

a) DPP-4i: Potential risk of pancreatitis and joint pain.

b) SGLT2i: Volume depletion, hypotension, genital fungal infections, ketoacidosis, Fournier's gangrene, acral amputations, and fractures; relatively contraindicated in individuals at risk of amputations and/or fractures. c) GLP1-RA: Nausea, vomiting, and diarrhea, generally mild to moderate and transitory; contraindicated in individuals with a personal or family history of medullary thyroid carcinoma or multiple endocrine neoplasia type 2 .

\section{Cardiovascular Outcomes Trials Results in T2DM Transferred to Practice Guidelines}

How does all this evidence have been transferred to practice guidelines? Indeed, it all started with the 2018 European/American Consensus [40], and we now have excellent evidence-based guidelines 
around the world. All these guidelines recognize five clinical profiles susceptible to specific treatment and significant benefit in T2DM patients:

1. Atherosclerotic cardiovascular disease

2. Heart failure

3. Chronic kidney disease

4. Obesity

5. Hypoglycemic risk

The Standards of Medical Care in Diabetes-2020 [41] suggests the following algorithm. Metformin as first-line therapy and HbAlc $<7 \%$ as the general goal. GLP1-RA analogs and/or SGLT2i for individuals with atherosclerotic cardiovascular disease profile. SGLT2i and/or GLP1-RA analogs for individuals with heart failure or chronic kidney disease profiles. In individuals with obesity and/or hypoglycemia risk GLP1-RA analogs are excellent options (Figure 6).

The American Association of Clinical Endocrinologists and the American College of Endocrinology consensus (2020) [42] proposed a similar algorithm based on the HbAlc level and the clinical profile, with a GLP1-RA analog as the first option after metformin in highrisk patients. In September 2019, the European Association for the Study of Diabetes [43] proposed a disruptive algorithm with GLP1-RA analogs or an SGLT2i as the first option before metformin in patients with extremely high or high-risk new to this drug. In patients already treated with metformin, the European algorithm is like the American algorithm (Figure 7). Based on the cardiovascular disease continuum, in 2018 [44] our group proposed a framework to select between a GLP1-RA or a SGLT2i as the first line. If an atherothrombotic profile drives the death risk, a GLP1-RA analog should be the first option. If

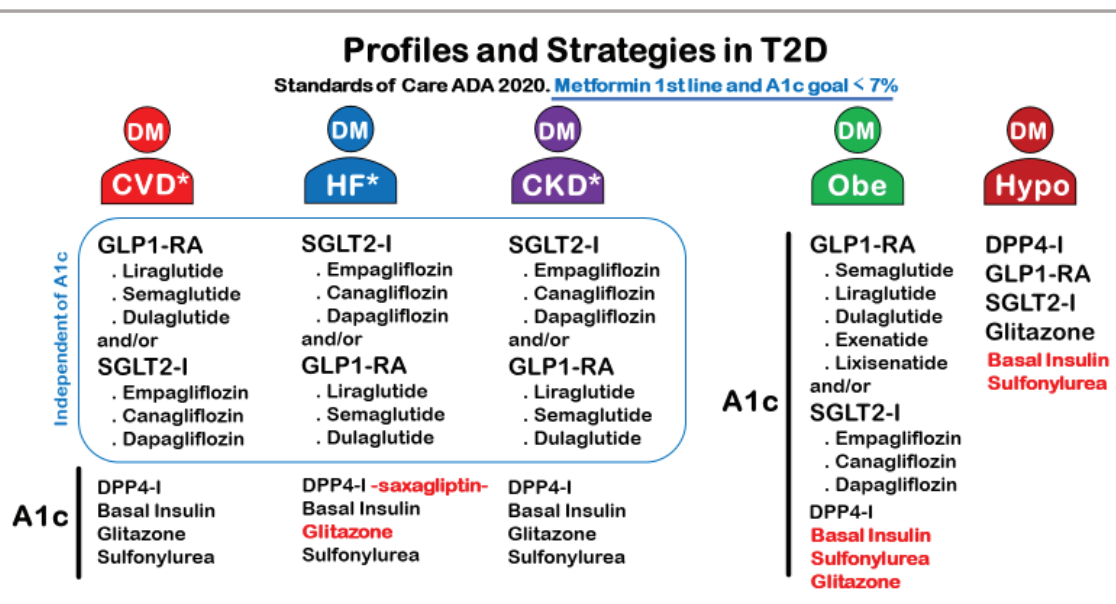

Figure 6: Summary of the American Diabetes Association 2020 standard of medical care for T2DM in the five clinical profiles.

In individuals with high risk or with CVD, HF and/or CKD, the use of GLP1-RA and/or SGLT2 inhibitors has demonstrated benefit and should be used independently of the HbA1c level.

$\mathrm{CVD}=$ Cardiovascular Disease; HF=Heart Failure; $C K D=C h r o n i c$ Kidney Disease; Obe=Obesity; Hypo=Hypoglycemic risk

\section{Profiles and Strategies in T2D MTF naives Guídelines ESC-EASD 2019}
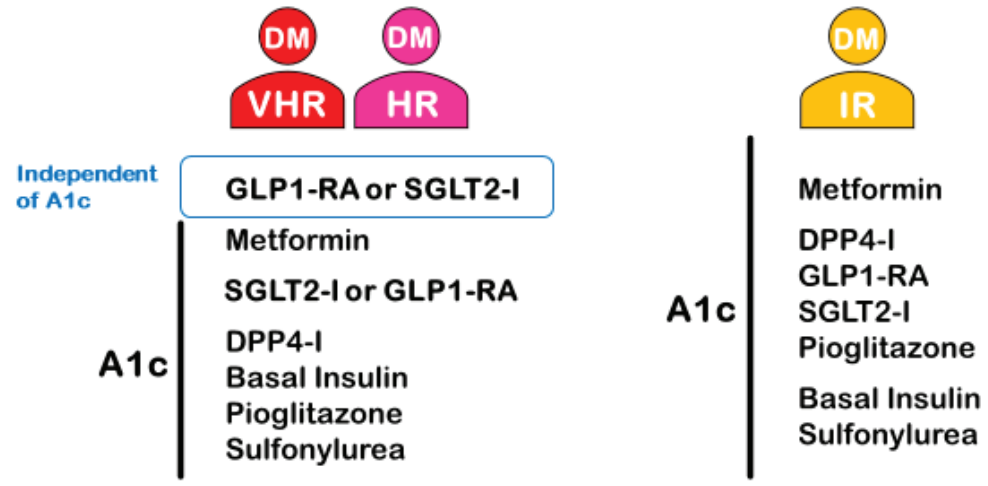

Figure 7: Summary of the ESC/EASD 2019 guidelines for T2DM.

These guidelines recommend starting with a GLP1-RA or a SGLT2-I as first line treatment, independent of the HbA1c level, for individuals naïve to metformin and with very high risk or high risk

MTF=Metformin; VHR=Very High Risk; HR=High Risk, IR=Intermediate Risk; ESC/EASD=European Society of Cardiology/European Association for the Study of Diabetes 
the death risk is associated with heart failure and/or chronic kidney disease profile, an SGLT2i should be the first option. However, frequently both types of drugs are needed.

In 2020, as never before, we can offer a significant cerebral, cardiac, and renal risk reduction to patients living with type 2 diabetes mellitus.

\section{References}

1. Alegre-Díaz J, Herrington W, López-Cervantes M, Gnatiuc L, Ramirez $\mathrm{R}$, et al. (2016) Diabetes and Cause-Specific Mortality in Mexico City. N Engl J Med 375: 1961-1971.

2. Gaede P, Vedel P, Parving HH, Pedersen O (1999) Intensified Multifactorial Intervention in Patients with Type 2 Diabetes Mellitus and Microalbuminuria: The Steno Type 2 Randomized Study. Lancet 353: 617-622.

3. Gaede P, Lund-Andersen H, Parving HH, Pedersen O (2008) Effect of a Multifactorial Intervention on Mortality in Type 2 Diabetes. N Eng J Med 358: 580-591.

4. Gaede P, Vedel P, Larsen N, Jensen GVH, Parving HH, et al. (2003) Multifactorial Intervention and Cardiovascular Disease in Patients with Type 2 Diabetes. N Engl J Med 348: 383-393.

5. Rawshani A, Rawshani A, Franzén S, Eliasson B, Svensson A, et al. (2017) Mortality and Cardiovascular Disease in Type 1 and Type 2 Diabetes. N Engl J Med 376: 1407-1418.

6. Rawshani A, Rawshani A, Franzén S, Sattar N, Eliasson B, et al. (2018) Risk Factors, Mortality, and Cardiovascular Outcomes in Patients with Type 2 Diabetes. N Engl J Med 379: 633-644.

7. Jensen MH, Kjolby M, Hejlensen O, Jakobsen PE, Vestergaard P (2020) Risk of Major Adverse Cardiovascular Events, Severe, Hypoglycemia, and All-Cause Mortality for Widely Used Antihyperglycemic Dual and Triple Therapies for Type 2 Diabetes Management: A Cohort Study of all Danish Users. Diabetes Care 43: 1209-1218.

8. Morales-Villegas E (2020) Control with Cardiologic Emphasis for Type 2 Diabetes Mellitus in the 2020. In: Morales-Villegas E (eds) Cardio Diabetology. $2^{\text {nd }}$ Edition.

9. Stratton IM, Adler Al, Neil HA, Matthews DR, Manley SE, et al. (2000) Association of Glycaemia with Macrovascular and Microvascular Complications of Type 2 Diabetes (UKPDS 35): Prospective Observational Study. BMJ 321: 405-412.

10. Action to Control Cardiovascular Risk in Diabetes Study Group, Gerstein HC, Miller ME, Byington RP, Goff DC Jr, et al. (2008) Effects of Intensive Glucose Lowering in Type 2 Diabetes. N Engl J Med 358: 2545-2559.

11. ADVANCE Collaborative Group, Patel A, MacMahon S, Chalmers J, Neal B, et al. (2008) Intensive Blood Glucose Control and Vascular Outcomes in Patients with Type 2 Diabetes. N Engl J Med 358: 25602572.

12. Duckworth W, Abraira C, Moritz T, Reda D, Emanuele N, et al. (2009) Intensive Glucose Control and Complications in American Veterans with Type 2 Diabetes. N Engl J Med 360: 129-139.

13. Nissen SE, Wolsky K (2007) Effect of Rosiglitazone on the Risk of Myocardial Infarction and Death from Cardiovascular Causes. N Engl J Med 356: 2457-2471.

14. US Food and Drug Administration (FDA) (2020) Diabetes MellitusType 2 Diabetes Mellitus: Evaluating the Safety of New Drugs for Improving Glycemic Control Guidance for Industry. Center for Drug Evaluation and Research, Rockville, USA.
15. Scirica BM, Bhatt DL, Braunwald E, Steg PG, Davidson J, et al. (2013) Saxagliptin and Cardiovascular Outcomes in Patients with Type 2 Diabetes Mellitus. N Engl J Med 369: 1317-1326.

16. White WB, Cannon CP, Heller SR, Nissen SE, Bergenstal RM, et al. (2013) Alogliptin after Acute Coronary Syndrome in Patients with Type 2 Diabetes. N Engl J Med 369: 1327-1335.

17. Green JB, Bethel MA, Armstrong PW, Buse JB, Engel SS, et al. (2015) Effect of Sitagliptin on Cardiovascular Outcomes in Type 2 Diabetes. N Engl J Med 373: 232-242.

18. Rosenstock J, Perkovik V, Johansen OE, Cooper ME, Kahn SE, et al. (2019) Effect of Linagliptin vs. Placebo on Major Cardiovascular Events in Adults with Type 2 Diabetes and High Cardiovascular and Renal Risk: The CARMELINA Randomized Clinical Trial. JAMA 321: 69-79.

19. Rosenstock J, Kahn SE, Johansen OE, Zinman B, Espeland MA, et al. (2019) Effect of Linagliptin vs. Glimepiride on Major Cardiovascular Outcomes in Adults with Type 2 Diabetes: The CAROLINA Randomized Clinical Trial. JAMA 322: 1155-1166.

20. Pfeffer MA, Claggett B, Diaz R, Dickstein K, Gerstein HC, et al. (2015) Lixisenatide in Patients with Type 2 Diabetes and Acute Coronary Syndrome. N Engl J Med 373: 2247-2257.

21. Marso SP, Daniels GH, Brown-Frandsen K, Kristensen P, Mann JFE, et al. (2016) Liraglutide and Cardiovascular Outcomes in Type 2 Diabetes. N Engl J Med 375: 311-322.

22. Marso SP, Bain SC, Consoli A, Eliaschewitz FG, Jódar E, et al. (2016) Semaglutide and Cardiovascular Outcomes in Type 2 Diabetes. $\mathrm{N}$ Engl J Med 375: 1834-1844.

23. Husain M, Birkenfeld AL, Donsmark M, Dungan K, Eliaschewitz FG, et al. (2019) Oral Semaglutide and Cardiovascular Outcomes in Patients with Type 2 Diabetes. N Engl J Med 381: 841-851.

24. Holman RR, Bethel MA, Mentz RJ, Thompson VP, Lokhnygina $Y$, et al. (2017) Effects of Once-Weekly Exenatide on Cardiovascular Outcomes in Type 2 Diabetes. N Engl J Med 377: 1228-1239.

25. Hernandez AF, Green JB, Janmohamed S, D'Agostino RB, Granger CB, et al. (2018) Albiglutide and Cardiovascular Outcomes in Patients with Type 2 Diabetes and Cardiovascular Disease (Harmony Outcomes): A Double-Blind, Randomized, Placebo-Controlled Trial. Lancet 392: 1519-1529.

26. Gerstein HC, Colhoun HM, Degenais GR, Diaz R, Lakshmanan M, et al. (2019) Dulaglutide and Cardiovascular Outcomes in Type 2 Diabetes (REWIND): A Double-Blind, Placebo-Controlled Trial. Lancet 394: 121-130.

27. Zinman B, Wanner C, Lachin JM, Fitchett D, Bluhmki E, et al. (2015) Empagliflozin, Cardiovascular Outcomes, and Mortality in Type 2 Diabetes. N Engl J Med 373: 2117-2128.

28. Neal B, Perkovic V, Mahaffey KW, de Zeeuw D, Fulcher G, et al. (2017) Canagliflozin and Cardiovascular and Renal Events in Type 2 Diabetes. N Engl J Med 377: 644-657.

29. Perkovic V, Jardine MJ, Neal B, Bompoint $S$, Heerspink HJL, et al. (2019) Canagliflozin and Renal Outcomes in Type 2 Diabetes and Nephropathy. N Engl J Med 380: 2295-2306.

30. Wiviott SD, Raz I, Bonaca MP, Mosenzon O, Kato ET, et al. (2019) Dapagliflozin and Cardiovascular Outcomes in Type 2 Diabetes. $\mathrm{N}$ Engl J Med 380: 347-357.

31. McMurray JJV, Solomon SD, Inzucchi SE, Køber L, Kosiborod MN, et al. (2019) Dapagliflozin in Patients with Heart Failure and Reduced Ejection Fraction. N Engl J Med 381: 1995-2008. 
32. Marso SP, McGuire DK, Zinman B, Poulter NR, Emerson SS, et al. (2017) Efficacy and Safety of Degludec versus Glargine in Type 2 Diabetes. N Engl J Med 377: 723-732.

33. Lau J, Bloch P, Schaffer L, Pettersson I, Spetzler J, et al. (2015) Discovery of the Once-Weekly Glucagon-Like Peptide 1 (GLP-1) Analogue Semaglutide. J Med Chem 58: 7370-7380.

34. Holst JJ (2007) The Physiology of Glucagon-like Peptide 1. Physiol Rev 87: 1409-1439.

35. Ussher JR, Drucker DJ (2012) Cardiovascular Biology of the Incretin System. Endocr Rev 33: 187-215.

36. Drucker DJ (2016) The Cardiovascular Biology of Glucagon-like Peptide 1. Cell Metab 24: 15-30.

37. Nauck MA, Meir JJ, Cavender MA, Abd El Aziz M, Drucker DJ (2017) Cardiovascular Actions and Clinical Outcomes with Glucagon-Like Peptide-1 Receptor Agonists and Dypeptidyl Peptidase-4 Inhibitors. Circulation 136: 849-870.

38. de Graff C, Donnelly D, Wootten D, Lau J, Sexton PM, et al. (2016) Glucagon-Like Peptide 1 and Its Class BG Protein-Coupled Receptors: A Long March to Therapeutic Successes. Pharmacol Rev 68: 954 1013.

39. Rakipovsky G, Rolin B, Nohr J, Klewe I, Frederiksen KS, et al. (2018) The GLP-1 analogs liraglutide and semaglutide reduce atherosclerosis in
ApoE $\%$ and $\mathrm{LDLr}^{\%}$ mice by a mechanism that includes inflammatory pathways. JACC Basic Transl Sci 3: 844-857.

40. Davies MJ, D' Alessio D, Fradkin J, Kernan WN, Mathieu C, et al. (2018) Management of Hyperglycaemia in Type 2 Diabetes, 2018. A Consensus Report by the American Diabetes Association (ADA) and the European Association for the Study of Diabetes (EASD). Diabetes Care 41: 2669-2701.

41. American Diabetes Association (2020) Standards of Medical Care in Diabetes-2020. Diabetes Care 43: S1-S206.

42. Garber AJ, Handelsman Y, Grunberger G, Einhorn D, Abrahamson MJ, et al. (2020) Consensus Statement by The American Association of Clinical Endocrinologists and American College of Endocrinology on the Comprehensive Type 2 Diabetes Management Algorithm-2020 Executive Summary. Endocr Pract 26: 107-139.

43. Cosentino F, Grant PJ, Aboyans V, Bailey CJ, Ceriello A, et al. (2019) 2019 ESC Guidelines on Diabetes, Pre-Diabetes and Cardiovascular Disease Developed in Collaboration with EASD. Euro Heart J 41: 255323.

44. Morales-Villegas EC, Scirica BM (2018) Evolving from Glycocentrism to Cardiocentrism in T2DM Treatment-Five Lessons Learned and their Clinical Implications. SF J Diabetes Endocrin 2: 1-15. 